\title{
PENERAPAN METODE SMALL AREA ESTIMATION DENGAN PENDEKATAN KERNEL UNTUK MENDUGA PERSENTASE STUNTING DI INDONESIA
}

\author{
AYU RATNA SARI, IZZATI RAHMI HG, MAIYASTRI \\ Program Studi S1 Matematika, \\ Fakultas Matematika dan Ilmu Pengetahuan Alam, Universitas Andalas, \\ Kampus UNAND Limau Manis Padang, Indonesia. \\ email : ayuratnasari0528@gmail.com
}

Diterima 14 Oktober 2019 Direvisi 21 Oktober 2019 Dipublikasikan 3 Desember 2019

\begin{abstract}
Abstrak. Stunting merupakan salah satu masalah gizi pada balita yang masih tergolong cukup tinggi di setiap negara. Salah satu indikator yang digunakan adalah persentase stunting. Untuk melakukan pendugaan persentase stunting bisa dilakukan dengan program pengumpulan data melalui teknik survei. Berdasarkan program tersebut nilai dugaan dapat diduga secara langsung dan secara tidak langsung. Pada pendugaan langsung terdapat kelemahan yaitu tidak memiliki ketelitian yang cukup, sehingga akan menghasilkan nilai ragam yang sangat besar. Untuk mengatasi masalah tersebut, dapat digunakan metode tidak langsung yang dikenal dengan metode pendugaan area kecil (Small Area Estimation, SAE). SAE merupakan konsep terpenting dalam pendugaan parameter secara tidak langsung di suatu area. SAE dilakukan dengan menambahkan variabel penyerta yaitu persentase bayi mendapat ASI Eksklusif. Jika asumsi tidak lengkap, maka dapat digunakan pendekatan nonparametrik. Salah satu pendekatan nonparametrik yang digunakan adalah pendekatan Kernel dengan fungsi Gaussian. Evaluasi hasil pendugaan dilakukan dengan melihat nilai ragam dari pendugaan langsung dan pendugaan pendekatan Kernel. Hasil pendugaan pendekatan kernel dengan fungsi Gaussian adalah pendugaan terbaik, karena menghasilkan nilai ragam yang lebih kecil.
\end{abstract}

Kata Kunci: Penduga langsung, Small Area Estimation(SAE), Kernel-Gaussian

\section{Pendahuluan}

Persaingan antar bangsa di dunia semakin kompetitif, agar mampu bersaing dengan tenaga kerja dari Negara lain, maka butuh Sumber Daya Manusia (SDM) yang berkualitas. Kualitas SDM sangat bergantung pada kondisi gizi anak, jika gizi anak tercukupi maka anak tersebut akan optimal dalam tumbuh kembangnya, sesuai dengan kriteria begitu sebaliknya. Salah satu masalah gizi yang sering terjadi pada anak adalah stunting. Stunting merupakan masalah kurang gizi kronis yang disebabkan oleh kurangnya asupan gizi dalam waktu yang cukup lama, sehingga tinggi badan anak sangat pendek atau pendek dari standar usianya. Salah satu faktor yang mempengaruhi terjadinya stunting adalah ASI Eksklusif. Pada penelitian ini persentase bayi mendapat ASI Eksklusif dijadikan sebagai variabel penyerta. 
Dalam tulisan ini akan dibahas mengenai bagaimana menentukan nilai dugaan persentase stunting dan perbandingan nilai dugaan persentase stunting berdasarkan nilai ragam. Untuk melakukan pendugaan maka digunakan metode pendugaan langsung (direct estimation). Pada metode pendugaan langsung terdapat kelemahan yaitu tidak memiliki ketelitian yang cukup, sehingga akan menghasilkan nilai ragam yang sangat besar. Untuk mengatasi masalah tersebut, dapat digunakan metode tidak langsung (Indirect estimation) yang dikenal dengan metode pendugaan area kecil (Small Area Estimation, SAE). SAE merupakan pendugaan parameter yang dilakukan dengan melibatkan informasi tambahan baik dari dalam area yang menjadi perhatian maupun luar area. Secara statistik informasi tambahan tersebut memiliki sifat meminjam kekuatan. Jika tidak ada hubungan linier antara penduga langsung dan variabel tambahan maka pendugaan tidak langsung tidak dapat digunakan, sehingga digunakan pendekatan nonparametrik. Salah satu pendekatan nonparametrik yang digunakan adalah pendekatan Kernel.

\section{Landasan Teori}

\subsection{Pengertian Balita dan Status Gizi Balita}

Balita adalah anak dengan usia di bawah 5 tahun. Masa balita merupakan periode penting dalam proses tumbuh kembang anak. Status gizi merupakan suatu ukuran mengenai kondisi tubuh seseorang yang dapat dilihat dari makanan yang dikonsumsi dan penggunaan zat-zat gizi di dalam tubuh. Status gizi dapat dibedakan menjadi 3 indeks yaitu berdasarkan berat badan menurut umur $(\mathrm{BB} / \mathrm{U})$, tinggi badan menurut umur $(\mathrm{TB} / \mathrm{U})$, dan rasio berat badan dan tinggi badan (BB/TB) [2].

\subsection{Stunting}

Stunting dapat diketahui bila seorang anak sudah diukur panjang atau tinggi badannya, lalu dibandingkan dengan standar, dan hasilnya berada di bawah normal [5]. Menurut standar pertumbuhan anak dari World Health Organization (WHO), anak dikatakan stunting yaitu ketika panjang atau tinggi badan anak menunjukkan angka di bawah minus dua standar deviasi (SD).

\subsection{Pendugaan Langsung (Direct Estimation)}

Dalam konteks survei pendugaan parameter dengan pendugaan langsung didasarkan hanya pada data sampel yang diperoleh dari area tersebut [4]. Pendugaan langsung menggunakan nilai variabel yang menjadi perhatian hanya pada periode waktu dan unit sampel untuk area yang menjadi perhatian. Berikut ini merupakan taksiran pendugaan secara langsung $\left(\bar{y}_{i}\right)$ diperoleh dengan metode klasik atau dapat dirumuskan sebagai berikut:

$$
\bar{y}_{i}=\sum_{j=1}^{n_{i}} \frac{y_{i j}}{n_{i}} \quad ; \quad \text { dengan } i=1,2, \cdots, n \quad j=1,2, \cdots, n_{i}
$$

dengan : 


$$
\begin{aligned}
& \bar{y}_{i}=\text { pendugaan secara langsung area } k e-i \\
& y_{i j}=\text { unit ke- } j \text { di area ke- } i \\
& n_{i}=\text { ukuran sampel area } k e-i \\
& n=\text { banyaknya area yang tersurvei }
\end{aligned}
$$

Nilai ragam dari suatu pendugaan parameter memiliki peranan penting untuk diketahui, diantaranya adalah untuk mengukur seberapa baik penaksiran parameter yang diperoleh. Untuk menentukan nilai ragam pendugaan langsung dapat dicari dengan rumus sebagai berikut:

$$
s_{p l}^{2}=\frac{1}{n-1} \sum_{i=1}^{n}\left(\bar{y}_{i}-(\overline{\bar{y}})\right)^{2}
$$

dengan :

$$
\begin{aligned}
& s_{p l}^{2}=\text { ragam pendugaan langsung } \\
& \bar{y}_{i}=\text { pendugaan langsung area ke-i } \\
& \overline{\bar{y}}=\text { rata-rata pendugaan langsung untuk semua area } \\
& n=\text { banyaknya area yang tersurvei }
\end{aligned}
$$

\subsection{Pendugaan Area Kecil (Small Area Estimation)}

Pendugaan Area Kecil (Small Area Estimation) adalah metode yang digunakan untuk menduga parameter yang berasal dari area atau sub populasi dengan ukuran sampel yang kecil. Suatu area disebut kecil apabila contoh yang diambil tidak mencukupi untuk melakukan pendugaan langsung dengan hasil dugaan yang akurat [4]. Pendugaan area kecil dikelompokkan menjadi dua jenis model dasar, yaitu model level area (basic area level model) dan model level unit (basic unit level model) [4]. Model level area merupakan model yang didasarkan pada ketersediaan variabel indikator yang hanya ada untuk level area tertentu. Misalkan $x_{i}=\left(x_{1} i, x_{2} i, \cdots, x_{k} i\right)^{T}$ dengan parameter yang akan diduga adalah $\theta_{i}$ yang diasumsikan mempunyai hubungan dengan $x_{i}$. Variabel tersebut digunakan untuk membangun model, yaitu:

$$
\theta_{i}=\mathbf{x}_{i}^{T} \beta+v_{i} \quad i=1,2,3, \cdots, n
$$

dimana $n$ adalah banyaknya area kecil, dengan $\beta=\left(\beta_{1}, \beta_{2}, \beta_{3}, \cdots, \beta_{k}\right)^{T}$ merupakan vektor $k \times 1$ adalah koefisien regresi untuk variabel indikator $\mathbf{x}_{i}$, dan $v_{i}$ adalah pengaruh acak pada area kecil yang diasumsikan berdistribusi $N\left(0, \sigma_{v}^{2}\right)$ [4]. Penduga $\theta_{i}$ dapat diketahui dengan mengasumsikan bahwa model penduga langsung $\bar{y}_{i}$ telah tersedia, yaitu:

$$
\bar{y}_{i}=\theta_{i}+\varepsilon_{i} \quad i=1,2,3, \cdots, n
$$

dengan sampling error $\varepsilon_{i} \sim N\left(0, D_{i}\right)$ dengan $D_{i}$ diketahui.

Jika model pada persamaan (2.4) dan (2.3) digabungkan maka akan menghasilkan model gabungan (mixed models):

$$
\bar{y}_{i}=\mathbf{x}_{i}^{T} \beta+v_{i}+\varepsilon_{i} \quad i=1,2,3, \cdots, n
$$


Model gabungan diatas dikenal sebagai model Fay-Herriot [4].

\subsection{Pendugaan Area Kecil dengan Pendekatan Kernel}

Menurut Mukhophaday dan Maiti [3], hampir semua aplikasi dari pendugaan area kecil menggunakan asumsi linieritas. Jika hubungan antara penduga langsung dengan variabel penyerta tidak linier, maka tidak tepat "meminjam kekuatan" dari area lain dengan manggunakan model linier dalam pendugaan tak langsung (Indirect Estimation). Untuk mengatasi hal tersebut dikembangkan pendekatan nonparametrik. Salah satu pendekatan nonparametrik yang digunakan adalah pendekatan Kernel. Persamaan (2.3) dapat didekati dengan sebuah rumus yang lebih umum, yaitu:

$$
\theta_{i}=m\left(x_{i}\right)+v_{i} \quad i=1,2,3, \cdots, n
$$

dengan $i=1,2,3, \cdots, n$ menunjukkan jumlah area kecil. Fungsi $m\left(x_{i}\right)$ adalah fungsi pemulusan (smoothing function) yang mendefinisikan hubungan antara pendugaan langsung dan variabel penyerta pada area ke-i, $\theta_{i}$ adalah rataan area kecil pada area ke-i, $\bar{y}_{i}$ adalah pendugaan langsung area ke-i, $v_{i}$ merupakan pengaruh acak pada area ke-i dimana $v_{i} \sim N\left(0, \sigma_{v}^{2}\right)$ dan $\varepsilon_{i}$ merupakan sampling error pada area ke-i yang diasumsikan $\varepsilon_{i} \sim N\left(0, D_{i}\right)$ dengan $D_{i}$ diketahui [4]. Subtitusi persamaan (2.4) dan (2.6)akan menghasilkan sebagai berikut:

$$
\bar{y}_{i}=m\left(x_{i}\right)+v_{i}+\varepsilon_{i} \quad i=1,2,3, \cdots, n
$$

Untuk menentukan fungsi $m\left(x_{i}\right)$ dapat diduga dengan menggunakan persamaan Nadaraya-Watson Kernel [1] yaitu:

$$
\widehat{m}(x)=\frac{\sum_{i=1}^{n} K_{h}\left(x-x_{i}\right) y_{i}}{\sum_{i=1}^{n} K_{h}\left(x-x_{i}\right)} \quad i=1,2,3, \cdots, n
$$

dengan $K_{h}($.$) merupakan fungsi Kernel dengan h$ merupakan bandwidth. Lebar jendela atau bandwidth (h) merupakan parameter pemulusan (smoothing) yang berfungsi untuk menentukan kemulusan dari kurva yang dihasilkan. Pemilihan bandwidth yang dipilih adalah $h \propto n^{-1 / 5}$ [3]. Bentuk dari fungsi Kernel $K_{h}(u)$ dapat dinyatakan sebagai berikut:

$$
K_{h}(u)=\frac{1}{h} K\left(\frac{u}{h}\right)
$$

dengan syarat $K\left(\frac{u}{h}\right)$ merupakan simetris, kontinu dan terbatas, yaitu sebagai berikut:

(i) $K\left(-\frac{u}{h}\right)=K\left(\frac{u}{h}\right)$ simetris.

(ii) $K\left(\frac{u}{h}\right)$ terbatas dan kontinu pada daerah asal $K\left(\frac{u}{h}\right)$.

(iii) $\int K\left(\frac{u}{h}\right) \partial\left(\frac{u}{h}\right)=1$.

Pada tulisan ini digunakan fungsi Kernel Normal (Gaussian), yaitu:

$$
K\left(\frac{u}{h}\right)=\frac{1}{\sqrt{2 \pi}} \exp \left(-\frac{1}{2}\left(\frac{u}{h}\right)^{2}\right)-\infty<\left(\frac{u}{h}\right)<\infty
$$


Cara lain yang dapat digunakan untuk menduga fungsi $\widehat{m}(x)$ pada regresi nonparametrik adalah dengan menggunakan local averaging procedure atau rata-rata lokal terboboti sebagai fungsi pemulusan, yaitu:

$$
\widehat{m}(x)=\frac{1}{n} \sum_{i=1}^{n} W_{h i}(x) y_{i} \quad i=1,2,3, \cdots, n
$$

dengan $\widehat{m}(x)$ merupakan dugaan dari fungsi regresi pada area ke-i, $n$ merupakan banyaknya area yang tersurvei, $W_{h i}(x)$ merupakan fungsi pembobot pada area di sekitar $x_{i}$ dengan lebar jendela $h, y_{i}$ merupakan unit area ke-i [3]. Fungsi $W_{h i}(x)$ yang digunakan pada metode pemulusan Kernel (Kernel smoothers) adalah sebagai berikut:

$$
W_{h i}(x)=\frac{K_{h}\left(x-x_{i}\right)}{\frac{1}{n} \sum_{i=1}^{n} K_{h}\left(x-x_{i}\right)} \quad i=1,2,3, \cdots, n
$$

Menurut Mukhopadhay dan Maiti [3], dugaan parameter terbaik pada area ke-i, $\theta_{i}$ dapat dituliskan menjadi:

$$
\bar{\theta}_{i}^{\text {kernel }}=\bar{\gamma}_{i} y_{i}+\left(1-\bar{\gamma}_{i}\right) \widehat{m}(x)
$$

Nilai dugaan dari ragam antar area $\left(\sigma_{u}^{2}\right)$ dapat diperoleh dengan cara memilih nilai tertinggi dari hasil perhitungan [3] dengan rumus sebagai berikut:

$$
\widehat{\sigma}_{u}^{2}(x)=\max \left\{0, \frac{1}{n-1} \sum_{i=1}^{n} W_{h i}(x)\left[y_{i}-\widehat{m}(x)\right]^{2}-D\right\}
$$

Ragam untuk pendugaan tidak langsung adalah sebagai berikut:

$$
s_{p t l}^{2}=\frac{1}{n-1} \sum_{i=1}^{n}\left(\bar{\theta}_{i}^{\text {kernel }}-\overline{\bar{\theta}}^{\text {kernel }}\right)^{2}
$$

dengan :

$$
\begin{array}{ll}
s_{p t l}^{2} & =\text { ragam pendugaan tidak langsung } \\
\bar{\theta}_{i}^{\text {kernel }} & =\text { pendugaan Kernel area ke-i } \\
\overline{\bar{\theta}}^{\text {kernel }} & =\text { rata-rata pendugaan Kernel untuk semua area } \\
n & =\text { banyaknya area yang tersurvei }
\end{array}
$$

\section{Pembahasan}

\subsection{Pendugaan Langsung Persentase Stunting}

Berdasarkan hasil perhitungan dengan pendugaan langsung didapatkan nilai ratarata persentase stunting sebesar 31,0409 dengan nilai ragam 28,0635. Hasil pendugaan langsung persentase stunting di Indonesia adalah sebagai berikut: 
Tabel 1. Persentase stunting di Indonesia dengan Metode Pendugaan Langsung

\begin{tabular}{|c|l|c|}
\hline NO & Provinsi & Hasil Pendugaan Langsung \\
\hline 1 & Aceh & 35,2217 \\
2 & Sumatera Utara & 31,2030 \\
3 & Sumatera Barat & 30,6000 \\
4 & Riau & 29,1500 \\
5 & Jambi & 26,1909 \\
6 & Sumatera Selatan & 23,9471 \\
7 & Bengkulu & 29,8100 \\
8 & Lampung & 31,0000 \\
9 & Kepulauan Bangka Belitung & 27,4286 \\
10 & Kepulauan Riau & 22,6143 \\
11 & DKI Jakarta & 23,4500 \\
12 & Jawa Barat & 28,8481 \\
13 & Jawa Tengah & 28,3629 \\
14 & DI Yogyakarta & 21,6000 \\
15 & Jawa Timur & 26,5974 \\
16 & Banten & 29,7375 \\
17 & Bali & 20,6556 \\
18 & NTB & 37,1600 \\
19 & NTT & 39,9227 \\
20 & Kalimantan Barat & 36,8286 \\
21 & Kalimantan Tengah & 38,2214 \\
22 & Kalimantan Selatan & 35,7000 \\
23 & Kalimantan Timur & 31,0600 \\
24 & Kalimantan Utara & 34,4800 \\
25 & Sulawesi Utara & 31,0267 \\
26 & Sulawesi Tengah & 36,2923 \\
27 & Sulawesi Selatan & 36,0792 \\
29 & Sulawesi Tenggara & 36,5941 \\
30 & Gorontalo & 31,2000 \\
31 & Malawesi Barat & 40,6500 \\
32 & Maluku Utara & 31,3364 \\
33 & Papua Barat & 25,2700 \\
34 & Papua & 33,7154 \\
& & 33,4379 \\
\hline
\end{tabular}

\subsection{Pendugaan tidak langsung Persentase Stunting dengan Pendekatan Kernel}

\subsubsection{Pemilihan Variabel Penyerta}

Variabel yang akan dijadikan sebagai variabel penyerta adalah persentase bayi mendapatkan ASI Eksklusif yang di peroleh dari data Pemantauan Status Gizi (PSG) tahun 2017. Diperoleh nilai $r_{x y}=-0,200<r_{(0.025 ; 32)}=0,3388$ dan nilai $P$ - value $=0,258>\alpha=0.05$ maka terima $H_{0}$, berarti bahwa tidak terdapat hubungan linier yang signifikan antara persentase stunting di Indonesia dengan persentase bayi mendapat ASI Eksklusif. Karena tidak ada hubungan linier antara persentase stunting di Indonesia dengan persentase bayi mendapat ASI Eksklusif sehingga digunakan pendekatan area kecil dengan metode nonparametrik yaitu dengan menggunakan pendekatan Kernel. 


\subsubsection{Model Pendugaan dengan menggunakan Metode Pendekatan Kernel}

Setelah mendapatkan hasil bahwa tidak ada hubungan linier antara persentase stunting di Indonesia dengan persentase bayi mendapat ASI Eksklusif,maka dapat dilakukan dengan menghitung nilai fungsi pemulusan $\widehat{m}(x)$ dan nilai dugaan dari ragam antar area $\left(\widehat{\sigma}_{u}^{2}\right)$, dengan bandwidth sebesar $h \propto n^{-1 / 5} \approx 34^{-1 / 5} \approx 0,493974$. Diperoleh nilai dugaan maksimum $\left(\widehat{\sigma}_{u}^{2}\right)$ sebesar 84,1019 dengan nilai D sebesar 2,9772 dan fungsi pemulusan $\widehat{m}(x)$ dapat dilihat pada Tabel 2 .

Tabel 2. Persentase stunting di Indonesia dengan Metode Pendugaan Pendekatan Kernel

\begin{tabular}{|c|c|c|c|}
\hline NO & Provinsi & $\widehat{m}(x)$ & Dugaan persentase stunting $\left(\bar{\theta}_{i}^{\text {kernel }}\right)$ \\
\hline 1 & Aceh & 34,1162 & 35,6685 \\
\hline 2 & Sumatera Utara & 28,5009 & 28,5000 \\
\hline 3 & Sumatera Barat & 31,0756 & 30,5083 \\
\hline 4 & Riau & 29,4936 & 29,6949 \\
\hline 5 & Jambi & 31,4132 & 25,4460 \\
\hline 6 & Sumatera Selatan & 22,7990 & 22,8000 \\
\hline 7 & Bengkulu & 27,3099 & 29,3419 \\
\hline 8 & Lampung & 27,5608 & 31,5289 \\
\hline 9 & Kepulauan Bangka Belitung & 28,4262 & 27,3065 \\
\hline 10 & Kepulauan Riau & 30,0397 & 21,3660 \\
\hline 11 & DKI Jakarta & 22,7009 & 22,7000 \\
\hline 12 & Jawa Barat & 31,0486 & 29,2334 \\
\hline 13 & Jawa Tengah & 32,5961 & 28,5300 \\
\hline 14 & DI Yogyakarta & 19,8000 & 19,8000 \\
\hline 15 & Jawa Timur & 28,2848 & 26,7225 \\
\hline 16 & Banten & 32,5209 & 29,7766 \\
\hline 17 & Bali & 23,4741 & 19,3430 \\
\hline 18 & NTB & 35,6091 & 37,0052 \\
\hline 19 & NTT & 36,5939 & 40,1998 \\
\hline 20 & Kalimantan Barat & 34,9637 & 35,4693 \\
\hline 21 & Kalimantan Tengah & 30,0397 & 36,7654 \\
\hline 22 & Kalimantan Selatan & 33,3758 & 34,1549 \\
\hline 23 & Kalimantan Timur & 29,1437 & 30,5978 \\
\hline 24 & Kalimantan Utara & 31,8219 & 33,2678 \\
\hline 25 & Sulawesi Utara & 33,9494 & 31,5494 \\
\hline 26 & Sulawesi Tengah & 34,4729 & 34,0898 \\
\hline 27 & Sulawesi Selatan & 31,7772 & 34,7484 \\
\hline 28 & Sulawesi Tenggara & 35,3971 & 36,3744 \\
\hline 29 & Gorontalo & 31,6991 & 31,7000 \\
\hline 30 & Sulawesi Barat & 34,7010 & 37,9270 \\
\hline 31 & Maluku & 29,0855 & 29,9778 \\
\hline 32 & Maluku Utara & 27,1396 & 25,1298 \\
\hline 33 & Papua Barat & 34,3073 & 33,3362 \\
\hline 34 & Papua & 31,8254 & 32,7836 \\
\hline
\end{tabular}

\subsection{Perbandingan nilai dugaan persentase stunting di Indonesia berdasarkan hasil pendugaan langsung dan pendugaan pendekatan Kernel.}

Berdasarkan nilai ragam persentase stunting di Indonesia tahun 2017 dari hasil pendugaan langsung sebesar 28,0635, dan nilai ragam persentase stunting di Indonesia tahun 2017 dari hasil pendugaan pendekatan Kernel sebesar 27,8428. Hal ini menunjukkan bahwa pendugaan pendekatan Kernel lebih baik digunakan, karena meng- 
24 Ayu Ratna Sari, dkk

hasilkan nilai ragam yang lebih kecil daripada menggunakan metode pendugaan langsung.

\section{Kesimpulan}

Pendugaan tidak langsung dengan pendekatan Kernel menghasilkan nilai ragam yang lebih kecil yaitu sebesar 27,8428 daripada nilai ragam menggunakan pendugaan langsung yaitu sebesar 28,0635. Oleh karena itu, metode pendugaan pendekatan Kernel lebih baik dibandingkan dengan metode pendugaan langsung.

\section{Daftar Pustaka}

[1] Hardle, W. 1994. Applied Nonparametric Regression. http://www.quantlet.com [diakses 24 September 2018]

[2] Kementerian Kesehatan Republik Indonesia. 2018. Buku Saku Pemantauan Status Gizi Tahun 2017. Badan Litbangkes Depkes RI 2018, Jakarta

[3] Niashinta, B, dkk. 2016. Pendugaan Area kecil terhadap pengeluaran per kapita di kabupaten Sragen dengan Pendekatan Kernel. Jurnal Gaussian, 5(1). ISSN : 2339-2541

[4] Rao, J. N. and I. Molina. 2015. Small Area Estimation. $2^{\text {nd }}$ edition. New Jersey : John Willey and Sons, Inc.

[5] TNP2K. 2017. 100 Kabupaten/Kota Prioritas untuk Intervensi Anak Kerdil (Stunting). Sekretariat Wakil Presiden Republik Indonesia, Jakarta Pusat

[6] Walpole, R. E. 1995. Pengantar Statistika. Edisi Ketiga. PT Gramedia Pustaka Utama. Jakarta. 